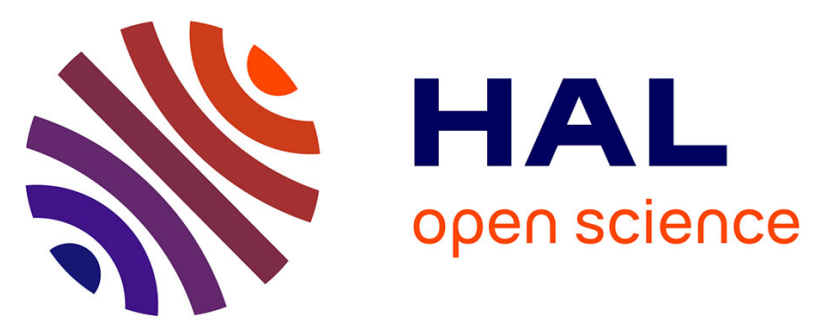

\title{
Team Sports Players' Observed Aggresion as a Function of Gender, Competitive Level, and Sport Type
}

\author{
Genevieve Cabagno, Olivier Rascle
}

\section{To cite this version:}

Genevieve Cabagno, Olivier Rascle. Team Sports Players' Observed Aggresion as a Function of Gender, Competitive Level, and Sport Type. Journal of Applied Social Psychology, 2006, 36 (8), pp.1980-2000. 10.1111/j.0021-9029.2006.00090.x . hal-02156907

\section{HAL Id: hal-02156907 https://hal.science/hal-02156907}

Submitted on 18 Jun 2019

HAL is a multi-disciplinary open access archive for the deposit and dissemination of scientific research documents, whether they are published or not. The documents may come from teaching and research institutions in France or abroad, or from public or private research centers.
L'archive ouverte pluridisciplinaire HAL, est destinée au dépôt et à la diffusion de documents scientifiques de niveau recherche, publiés ou non, émanant des établissements d'enseignement et de recherche français ou étrangers, des laboratoires publics ou privés. 
Running Head: GENDER AND OBSERVED AGGRESSION IN TEAM SPORTS

Team Sports Players' Observed Aggresion as a Function of Gender, Competitive Level, and Sport Type

Geneviève Coulomb-Cabagno and Olivier Rascle

Laboratory "Centre de Recherches sur l'Education, les Apprentissages et la Didactique", UFRAPS, University of Rennes 2, France.

Correspondence concerning this article should be addressed to G. Coulomb-Cabagno, UFRAPS, University of Rennes 2, Avenue. C. Tillon, 35044 Rennes Cedex, France. E-mail : genevieve.cabagno@uhb.fr 


\begin{abstract}
This study aims at examining observed aggression in team sports as a function of gender, competitive level, and sport type. It was hypothesized that (a) male players display more aggressive behaviors than female players, (b) aggressive behaviors increase when competitive level rises, and (c) gender difference in observed aggression is depending on sport type. One hundred and eighty games, equally shared among males and females, soccer and handball, and departmental, regional and national competitive levels were recorded on videotapes and observed using a grid to differ instrumental from hostile aggressive behaviors. The results revealed that male players always display more aggressive behaviors than female players, whatever the sport, the competitive level or the nature of the observed aggression; instrumental aggressive behaviors increase and hostile aggressive behaviors decrease when competitive level rises; and the gender difference appears larger in handball than in soccer.
\end{abstract}


Team Sports Players' Observed Aggression as a Function of Gender, Competitive Level and Sport Type

If the gender differences have been largely reported in the scientific literature in terms of behaviors, attitudes or beliefs, the authors do not agree on their ways or nature (Cohn, 1991; Lytton \& Romney, 1991). Yet, there is a personality dimension for which the authors seem to agree, that is aggressiveness. In academic context, the tendency for men to manifest a higher level of aggressiveness and / or to display more aggression than women is well documented (Buss \& Perry, 1992; Eagly \& Steffen, 1986; Hyde,1984). For instance, Buss and Perry (1992) reported that males had significantly higher scores on physical and verbal aggressions than women.

Aggressiveness is generally defined as an element of the individual's personality, whereas aggression refers to the intent to harm the other either physically or psychologically. In sport psychology, despite the lack of consensus on the definition, one that is often accepted is behavior transgressing the rules of the considered activity with the intent to harm someone either psychologically or physically (Tenenbaum, Stewart, Singer, \& Duda, 1996). In this context, gender / sport relations represent a relatively new content area, especially when we pay attention to this aggression thematic.

Sport, as a social practice, is actively involved in the individuals' socialization and one often highlights the role it plays in developing moral values such as support, fair play, solidarity or cooperation. However, certain authors tend to point out the ambiguous relationship that seems to be building up between sport and aggression, more especially in competitive sport where "achievement of goals (scoring and winning) is predicated on the successful utilization of violence" (Messner, 1990a, p. 203). According to Stephens (1998), competitive sport frequently rewards aggressions even though they are contrary to social norms. Everything happens as if the performance-related stakes surpassed the socially 
desirable moral values. In the same way, Bredemeier (1994) showed that male players in general had a tendency to consider aggression as more legitimate than those individuals not practicing any sport. Some male players even consider aggressions as competencies (Messner, 1990a). Nonetheless, males and females do not seem to be similarly affected by this process (Bredemeier, 1985; Silva, 1983).

\section{Gender and Aggression in Sport}

Gender is one of the first social categories children acquire and judgments about what is appropriate for men and women are affected (Biernat, 1991). People progressively develop differentiated judgments about femininity and masculinity, and some attitudes or behaviors are related to masculine features, whereas others are considered as feminine ones. Aggressiveness and aggression are generally perceived as masculine characteristics, and appear to be in contradiction with attitudes or behaviors considered as appropriate for women (Eagly \& Steffen, 1986). These authors contended that whereas "the male gender role includes norms encouraging many form of aggression [...], the traditional female gender role places little emphasis on aggression" (p. 310). This assumption could explain why many studies point out the differences between males and females in the perceived legitimacy of sport aggression, the degree of fair-play or the actual implementation of such behaviors (Bredemeier, 1985; Conroy, Silva, Newcomer, Walker, \& Johnson, 2001; Duda, Olson, \& Templin, 1991; Silva, 1983). Silva (1983) investigated male and female students' perceptions of the legitimacy of rule-violating behaviors by showing them slides depicting such behaviors in various sports. The results revealed that male players rated these behaviors as more legitimate than female players did. Bredemeier (1985) and Duda et al. (1991) used the "Continuum of Injurious Acts" among high school and college basketball players and obtained similar results with male players considering such acts as more legitimate than female players did. Such a perception of the legitimacy of the aggression would match with 
the athletes' fair play attitudes, with females perceiving the non fair play game as less acceptable than males would do (Duda et al., 1991). Recently, Conroy et al. (2001) as well as Tucker and Parks (2001) used the "Sport Behavior Inventory" (SBI) to assess the perception of the legitimacy of sport aggression. The scores of male and female children and adults (8 to 24 years old) once again showed that males perceived aggression in sport as being significantly more acceptable than females did.

Such results are fully convergent, but some authors regret these studies measure the perception of the legitimacy of aggression without considering the actual behaviors of the players (Cox, 1985; Kirker, Tenenbaum, \& Mattson, 2000; Stephens \& Bredemeier, 1996). The difficulty to observe underlying intention (main concept in sport definition) in aggression (Stephens, 1998) could explain why direct observation method has rarely been implemented in studying sport aggression. And yet, as Conroy et al. (2001, p. 417) pointed out, "a socially desirable response bias favoring prescribed responses to questions about the legitimacy of aggressive sport behavior" could exist. And Loughead and Leith (2001) and Worrell and Harris (1986) obtained non-significant or negative correlations between the behaviors actually observed and the perception of legitimacy of aggressive sport behaviors. Behavioral measures of aggression could be referred only to observable criteria and either ignore or make assumptions about the participants' intentions. In that perspective, Sheldon and Aimar (2001) proposed that "willingly engaging in behavior that could result in injury to another person is conceptually similar to intentionally trying to injure someone" (p. 305). They recognized "that the intent to harm and the willingness to harm are distinct constructs; however, they both represent a state of physiological and psychological readiness to do harm" (p. 305). Thus they believed that "a combination of either of these cognitive processes (i.e., intent or willingness) with a forceful physical act results in a behavior that can be classified, in a broad sense, as aggressive" (p.305). So, in their study, they recorded each aggressive incident that warrants a 
penalty by the rules of the game (even if the referee did not penalize the athlete). In a similar perspective, Pfister and Sabatier (1994) considered as aggressive behaviors all the behaviors transgressing the rules of the game (intentional or not, penalized or not by the referee) and leading to hurt or compel another person. They indicated the male players displayed more aggressive behaviors than the female players did, both in terms of instrumental and hostile aggressions. Such a distinction has been traditionally described in psychology (Bredemeier,1978; Rascle, Coulomb, \& Pfister, 1998; Tenenbaum et al., 1996 ). In both type of aggression, a target person is injured either physically and / or psychologically. Nevertheless, the purpose of hostile aggression is to do harm for its own sake whereas the purpose of instrumental aggression is to achieve a competitive advantage in the game and may be considered as means to serve future goals. In other words, instrumental aggression involves hurting another person as a means to an end (i.e., irregular tackling to stop an opponent going to score) and is directly related to the play itself. On the other hand, hostile aggression is intended to injure with the reinforcement coming from the victim being injured (i.e., hitting an opponent which has just committed an aggression against the player), and is not directly related to the play itself. Whereas this distinction has clearly been identified, it has been very little taken into consideration in sport, especially when male and female games are being compared.

\section{Gender, Competitive Level and Aggression}

If the gender difference regarding the perception of the legitimacy (or the use) of aggression may be well established, some structural factors seem however to be likely to influence such differences. Among those factors, the competitive level came to the researchers' attention. Indeed, sport aggression is perceived as being more legitimate as the level of competition increases (Bredemeier, 1985; Conroy et al., 2001; Silva, 1983). According to Conroy et al. (2001), such a score may be explained by the fact that the male 
players' perceptions of the reinforcement structures vary between the various levels of competition, with male players granting more tolerance and acceptance of aggression as the competitive level increases. Using an observation method, Coulomb and Pfister (1998) showed the number of instrumental aggressive behaviors in soccer was significantly higher in national level players (the highest competitive level in French soccer championship) than in the departmental players (the lowest competitive level in French soccer championship). On the other hand, players displayed less and less hostile aggressive behaviors as the competitive level increased. The authors explained these results by a more and more controlled and strategic use of the instrumental aggressive behaviors as the competitive level rises, such behaviors being progressively perceived as performance-oriented behaviors (Ryan, Williams, \& Wimer, 1990). This explanation corroborates Messner's comments expressed above (Messner, 1990a). Similarly, hostile aggressive behaviors would look like obstacles to performance and this kind of response would then be progressively inhibited as the competitive level rises.

If the trend for perceiving legitimacy or for implementing aggression according to the competitive level has been clearly established for males, the results for females are significantly less conforming. Some authors pointed out that sport aggression is perceived by females, like males, as being more legitimate as the competitive level increases (Conroy et al., 2001; Silva, 1983), but others showed adversary results or no significant difference for females across competitive levels (Ryan, Williams, \& Wimer, 1990). To our knowledge, no study has ever tried to verify the effect of the competitive level on actual aggressive behaviors among female players. If aggression is generally related to masculine features (Eagly \& Steffen, 1986), females' aggression may be perceived as a challenging gender role behavior. According to Nixon (1997), some factors, such as involvement in contact-sports, may encourage females to display behaviors challenging gender roles. We may assume that 
competitive level may reinforce the effect of involvement in contact-sports, the aggressions being progressively integrated as tools to serve performance.

Gender, Sport Type and Aggression

To our minds, the sport type factor has to be included in the thinking process. Metheny emphasized that "the socially sanctioned image of femininity and masculinity are always relative. They differ from era to era, from culture to culture and from group to group within a given social organization" (1965, p. 48). Indeed, all sports are not as similarly open to female players. Several authors pointed out sports were becoming stereotyped as masculine, feminine or neutral as a result of socialization and gender appropriateness (Csizma, Wittig, \& Schurr, 1988; Koivula, 1995, 2001; Riemer \& Visio, 2003). Masculine-typed sports generally refer to competitive sports, to confrontation or domination where aggressiveness and strength are largely prevailing - boxing, team sports, weightlifting - whereas feminine-typed sports are more oriented towards aestheticism, grace, flexibility - dancing, figure skating - (Koivula, 2001). According to Messner (1990b), sports characterized by aggressiveness, power and strength would allow males to affirm their masculine status and to build their masculinity. Females taking in activities perceived as not appropriate to their gender, such as team sports, are often mocked and insulted. They are often qualified as tomboys (Colley, Roberts, \& Chipps, 1985). Soccer is generally perceived as a masculine-typed sport. For example, Koivula (1995) asked to 207 participants (104 women and 103 men) to assess their feelings about the appropriateness of men and women participating in different sports, using a 7-point scale (from $1=$ very appropriate for men to $7=$ not at all appropriate for men). The results indicated that soccer was classified as a masculine-typed sport by men $(M=2.80)$ and women $(M=3.32)$. Using a same Likert scale, but in a reverse direction, Coulomb (1996) also indicated that soccer was perceived by 116 participants (66 women and 50 men) as a masculine sport $(M=6.06$ for women and $M=5.83$ for men, the difference being no 
significant between men and women). These results confirmed those obtained by Csizma et al. (1988). Nevertheless, Riemer and Visio (2003) obtained quite different results. They showed that 4 th to 12 th grade subjects (190 boys and 175 girls) perceived soccer as a "neutral sport", as well appropriate for men and women. According to these authors, one explanation of the difference with others studies may be that stereotypes about this sport are evolving, in relation with the expansion of this practice among the American feminine population during the last twenty years. As Deaux and Lafrance (1998) emphasized, "when the proportion of women and men in a situation is highly skewed, gender is more likely to become an issue" (p. 789). So, the situation makes gender more or less salient. In France, female soccer players are underrepresented (only $2.4 \%$ of all the players, French Soccer Federation, 2003) and little attention is given to the female practice through the media and by the different educational institutions (school, university, federal structure, etc.). This could explain why French soccer is still perceived as a masculine-typed sport (Coulomb, 1996). On the other hand, handball is perceived as a more neutral sport (Coulomb, 1996, $M=4.38$ for women and $M=4.68$ for men, the difference being not significant between men and women, but significant between soccer and handball, for men and women) and more women are involved in this sport compared to soccer (about $35 \%$ of the handball players are women according to the French Ministry of Youth and Sports, 1999). Thus, one can assume that, in France, female soccer appears as a more challenging gender role sport type than female handball. In this context (soccer and aggression perceived as masculine), one might speculate that female soccer players take this "masculine" sport their own way, i.e., differently from males, and it could result in lower aggression.

To summarize, this research aims at studying French team sports players' observed aggression as a function of gender, competitive level and sport type. Thus, the first objective of the present research is precisely to study how French team sports players' aggressive 
behaviors vary as a function of gender; the second objective of the research is to study how the two types of aggressive behaviors (instrumental and hostile behaviors) occur among males and females; and the third objective of the research is to study how aggressive behaviors occur among males and females in team sports as a function of the competitive level and the type of sport.

We hypothesize that (a) male players display aggressive behaviors more than female players do, (b) male and female players display more aggressive behaviors as the competitive level increases, and (c) the difference between males and females' aggressive behaviors will not be identical according to sport type, being not so large in handball as in soccer.

\section{Method}

\section{Materials}

The sample of this study consisted of one hundred and eighty handball $(\mathrm{N}=90)$ and soccer $(\mathrm{N}=90)$ games of French championships, equally divided into female and male games (45 female matches and 45 male matches for each sport). Three competitive levels were taken into account: the national level (the highest competitive level in French handball and soccer championships), the regional level (intermediary level in French handball and soccer championships) and the departmental level (the lowest competitive level in French handball and soccer championships). The games were equally distributed between the three competitive levels (i.e., 15 games per level). For each of these levels, the highest sub-category was chosen to represent the competitive level: in soccer championship, the national level is made of five sub-categories, the regional level is made of four sub-categories, and the departmental level is made of six sub-categories; in handball, the national level is made of five sub-categories, the regional level is made of four sub-categories, and the departmental level is made of five sub-categories ( 2 in female championship). Each sub-category being 
made of 18 to 20 teams, 15 different teams were chosen to compose the sample in the aim to avoid a "team effect"; each of these 15 teams was considered in two different contexts (once as a local team and once as a visitor team) to obtain the 15 games.

\section{Instruments}

All the games were recorded on videotapes. The coaches and players gave us their consent for the recordings. All the aggressive behaviors (as defined by Pfister \& Sabatier, 1994, and Sheldon \& Aimar, 2001) displayed by players during the totality of the games were observed and reported using two distinct observation grids, one for handball and one for soccer. These grids were recently used by Coulomb and Pfister (1998) for soccer and by Rascle et al. (1998) for handball. They differentiate the instrumental from the hostile aggressive behaviors through various behavioral categories labeled "illegal tackling or tripping", "holding", "striking", "against the opponents", "against the referees" and "against the teammates" in soccer and "repelling", " retaining", "hitting", "against the opponents", "against the referees" and "against the teammates" in handball. For both sport, a two-factor structure emerged from the exploratory factor analyses performed, the first three categories referring to instrumental aggressive behaviors and the other three to hostile aggressive behaviors.

Procedure

Phase 1. Two games were first observed in their totality (one in soccer and one in handball), in order to distinguish aggressive behaviors from other forceful behaviors (According to Silva, 1980, aggressive behaviors have to be distinguished from assertive behaviors, which are forceful behaviors but authorized by the rules of the game). Four observers familiarized with soccer and/or handball performed these observations, the two authors and two soccer coaches for the soccer game, and the two authors associated with two handball coaches for the handball game. Inter-observers agreements analysis (Kappa 
coefficients) were satisfactory, ranging between .91 and .94 for soccer and between .88 and .92 for handball.

Phase 2. Two others games (one in soccer and one in handball) were observed by the same teams of coders to establish the reliability of the grids. The behavioral categories used in the previous studies (Coulomb \& Pfister, 1998; Rascle et al., 1998) were adopted and the frequency of the aggressive behaviors (for the two teams as a whole) for each category was calculated. Inter-observers' agreements analysis (Kappa coefficients) were satisfactory, ranging respectively between .85 and .91 in soccer and .82 and .89 in handball for the various categories of instrumental aggressive behaviors, and between .89 and .95 in soccer and .87 and .94 in handball for the various categories of hostile aggressive behaviors.

Phase 3. The two authors observed the totality of the 180 games, reporting all coded aggressive behaviors (for the two teams as a whole) in adequate category for each game, and calculating the frequency for each category. Inter-observers' agreements (Kappa coefficients) were satisfactory, ranging respectively between .92 and .95 in soccer and .87 and .91 in handball for the various categories of instrumental aggressive behaviors and between .89 and .94 in soccer and .91 and .93 in handball for the various categories of hostile aggressive behaviors. Test-retest reliability was also tested by observing one soccer game and one handball game two months later. The Kappa coefficients were respectively .93 in soccer and .92 in handball.

Data from observations were then used for subsequent statistical tests. The aggressive behaviors observed in the three behavioral categories referring to instrumental aggression were gathered together in a single group and the same operation was conducted for the three categories referring to hostile aggression. So, a score of instrumental aggressive behaviors and a score of hostile aggressive behaviors (means between the two coders) were calculated for each game, observed in their totality. In order to compare handball and soccer, and given the 
different time periods between the two sports and between male and female games, the following analyses were performed on a standard 15-min period (the total number of instrumental aggressive behaviors displayed in one game was divided by the number of minutes making the duration of the game, and then multiplied by 15 to obtain this standard period. The same operation was conducted for hostile aggressive behaviors).

\section{Structural Validity}

Four confirmatory factor analyses were conducted using the LISREL 8.3 software (Jöneskog \& Sörbom, 1999) to test the factorial validity of the grids in handball and soccer. The overall goodness of fit of the models was tested using the chi-square likelihood ratio statistic $\left(\chi^{2}\right)$, Root Mean Square Error of Approximation (RMSEA), Goodness of Fit (GFI), Comparative Fit Index (CFI) and Non-Normed Fit Index (NNFI). Models were tested and assessed for one-factor and two-factor structures, both for handball and soccer. The two-factor structure was expected to present the best fit, with "illegal tackling", "holding", and "striking" categories in soccer and "repelling", "retaining", and "hitting" categories in handball correlating with the instrumental aggression variable and "opponent", "referee", and "teammate" categories correlating with the hostile aggression variable.

Results for the one-factor model in handball were unsatisfactory, $\chi^{2}(9, \mathrm{n}=90)=$ $22.35, p<.09, \mathrm{RMSEA}=.087(90 \% \mathrm{CI}=0.0-0.14), \mathrm{GFI}=.86, \mathrm{CFI}=.85$ and $\mathrm{NNFI}=.81$. Results for the two-factor model suggested a better fit: $\chi^{2}(8, \mathrm{n}=90)=12.23, p<.14$, RMSEA $=.077(90 \% \mathrm{CI}=0.01-0.16), \mathrm{GFI}=.96, \mathrm{CFI}=.95$, and $\mathrm{NNFI}=.91$. In soccer, results for the one-factor model were unsatisfactory too, $\chi^{2}(9, \mathrm{n}=90)=76.12, p<.001$, RMSEA $=.291$ $(90 \% \mathrm{CI}=0.23-0.35), \mathrm{GFI}=.78, \mathrm{CFI}=.79$, and NNFI $=.66$. A better fit was obtained with the two-factor model: $\chi^{2}(8, \mathrm{n}=90)=27.83, p<.001, \mathrm{RMSEA}=.168(90 \% \mathrm{CI}=0.10-0.24)$, $\mathrm{GFI}=.90, \mathrm{CFI}=.92$ and $\mathrm{NNFI}=.86$. Figure 1 presents the two-factor structural models with item factor regression coefficients. 


\section{Results}

4322 instrumental (79.80\%) and 1094 hostile (21.20\%) aggressive behaviors were observed during the 90 soccer games. 10782 instrumental (93.78\%) and 715 hostile (6.22\%) aggressive behaviors were observed during the 90 handball games. The Table shows team means (and standard deviations) of instrumental and hostile aggressive behaviors as a function of gender, competitive level and sport type, for a 15-min standard period. Two separate 2 (Gender) x 3 (Competitive level) multivariate analyses of variance procedures (one for soccer and one for handball) were carried out, with the instrumental and hostile aggressive behaviors displayed as the dependent variables. Alpha was established at .05 .

\section{Gender, Competitive Level and Aggressive Behaviors in Soccer}

The first MANOVA revealed a significant effect for gender, Wilks' lambda $(2,83)=$ $.045, p<.001$. Follow-up univariate analyses indicated that the male players displayed instrumental aggressive behaviors, $F(1,84)=1689.71, p<.001, \eta^{2}=.203$, and hostile aggressive behaviors, $F(1,84)=186.68, p<.001, \eta^{2}=.207$, more than the female players $\operatorname{did}(M=11.07 \pm 1.51$ vs. $M=3.47 \pm 1.47$ for instrumental aggressive behaviors and $M=2.95$ \pm 1.64 vs. $M=0.72 \pm 0.40$ for hostile aggressive behaviors).

The MANOVA also revealed a significant effect for competitive level, Wilks' lambda $(4,166)=.268, p<.001$, with significant univariate effects both for instrumental, $F(2,84)=$ $66.086, p<.001, \eta^{2}=.028$, and hostile aggressive behaviors, $F(2,84)=37.295, p<.001, \eta^{2}$ $=.068$. Scheffe test post-hoc analyses indicated that the players involved in departmental competitive level displayed instrumental aggressive behaviors less than those involved in regional level $(p<.01)$ and the latter less than the players involved in national competitive levels $(p<.001)$. Inversely, Figure 2 shows that the players of departmental level displayed more hostile aggressive behaviors than those involved in regional level $(p<.001)$, and the latter more than the players involved in national competitive level $(p<.03)$. 
Finally, a significant gender $\mathrm{x}$ competitive level interaction was also pointed out by the MANOVA, Wilks' lambda $(4,166)=.405, p<.001$, with significant univariate effects both for instrumental aggressive behaviors, $F(2,84)=19.19, p<.001$, and hostile aggressive behaviors, $F(2,84)=31.74, p<.001$. Scheffe post-hoc analyses revealed that gender difference was significant whatever the competitive level, both for instrumental and hostile aggressive behaviors $(p<.001)$. Nevertheless, as shown in Table 1, female players' instrumental aggressive behaviors increased linearly when competitive level rose while male players' instrumental aggressive behaviors decreased in regional level $(p<.03)$ and increased in national level $(p<.001)$. In the same way, a significant gender difference appeared for hostile aggressive behaviors, whatever the competitive level $(p<.001)$. Hostile aggressive behaviors decreased linearly for male players while no significant difference appeared across competitive level for female players (Table 1).

\section{Gender, Competitive Level, and Aggressive Behaviors in Handball}

Similar results were revealed. The MANOVA revealed a significant effect for gender, Wilks' lambda $(2,83)=.264, p<.001$. Follow-up univariate analyses indicated that the male players displayed instrumental aggressive behaviors, $F(1,84)=227.42, p<.001, \eta^{2}=.017$, and hostile aggressive behaviors, $F(1,84)=35.55, p<.001, \eta^{2}=.063$, more than the female players did $(M=33.88 \pm 4.30$ vs. $M=25.82 \pm 4.53$ for instrumental aggressive behaviors and $M=2.56 \pm 1.17$ vs. $M=1.40 \pm 0.88$ for hostile aggressive behaviors).

The MANOVA also revealed a significant effect for competitive level, Wilks' lambda $(4,166)=.346, p<.001$, with significant univariate effects both for instrumental aggressive behaviors, $F(2,84)=73.504, p<.001, \eta^{2}=.011$, and hostile aggressive behaviors, $F(2,84)$ $=11.664, p<.001, \eta^{2}=.040$. Scheffe test post-hoc analyses indicated that players involved in national level displayed instrumental $(p<.001)$ and hostile aggressive behaviors $(p<.03)$ more than those involved in regional level (Figure 3). 
Finally, a significant gender x competitive level interaction was also pointed out, Wilks' lambda $(4,166)=.346, p<.001$, with a significant univariate effect only for instrumental aggressive behaviors, $F(2,84)=18.412, p<.001$. Scheffe post-hoc analyses revealed that gender difference was significant, whatever the competitive level. Nevertheless, as shown in Table 1, female players' instrumental aggressive behaviors increased linearly when competitive level rose while male players' instrumental aggressive behaviors decreased in regional level $(p<.04)$ and increased in national level $(p<.001)$. No significant difference appeared for hostile aggressive behaviors.

Gender, Sport Type, and Aggressive Behaviors

$\mathrm{Chi}^{2}$ tests were performed in order to compare male and female frequencies of instrumental and hostile aggressive behaviors as a function of the sport type. The results revealed that even if the difference between male and female players' aggressive behaviors were significant both in soccer and in handball and whatever the competitive level, the breakdown was different. Indeed, female players' instrumental aggressive behaviors represented $23.86 \%$ of all the instrumental aggressive behaviors in soccer against $43,25 \%$ in handball, $\chi^{2}=8.40, p<.01$. On the other hand, female hostile aggressive behaviors represented $19.61 \%$ of all the hostile aggressive behaviors in soccer against $35.35 \%$ in handball, $\chi^{2}=6.20, p<.05$. Furthermore, variance explained by gender is larger in soccer than in handball, with respectively $20.3 \%$ vs. $1.7 \%$ for instrumental aggressive behaviors and $20.7 \%$ vs. $6.3 \%$ for hostile aggressive behaviors.

\section{Discussion}

The purpose of this research was to study French team sports players' observed aggressive behaviors as a function of gender, competitive level and sport type. We hypothesized that (a) male players would display aggressive behaviors more than female players do, (b) male and female players would display more aggressive behaviors as the 
competitive level increases, and (c) the difference between males and females' aggressive behaviors would not be identical according to sport type, being not so large in handball as in soccer.

\section{Gender and Aggression}

In line with the first hypothesis, the results showed that male players displayed instrumental and hostile aggressive behaviors more than female players did. Such results are congruent with most studies dealing with the gender variable, related to perception of legitimacy of aggression or actual observed behaviors, both in academic domain (Buss \& Perry, 1992; Eagly \& Steffen, 1986; Hyde, 1984) and in sport context (Bredemeier, 1985; Conroy et al., 2001; Pfister \& Sabatier, 1994; Silva, 1983; Tucker \& Parks, 2001). Aggression, and instrumental aggression in particular, is affected by the socialization process because it is primarily a learned behavior, reinforced through social modeling (Bandura, 1973). Thus, such a gender difference may be interpreted as the consequence of a differential socialization of males and females that tends to reinforce distinct behaviors for both sexes (Duru-Bellat \& Jarousse, 1996; Masters, Johnson, \& Kolodny, 1982). A differential socialization may imply the perception and acceptance of gender roles, i.e., roles in accordance with agreed expectations and social norms. Differentiated attitudes and behaviors are thus reinforced for males and females as a result of gender appropriateness, and aggressive behaviors are particularly representative of this categorization process (Eagly \& Steffen, 1986). Traditional stereotyped expectations generally consider aggressiveness or aggression, competition or risk-taking as masculine characteristics and appropriate behaviors for men while such attitudes or behaviors would not match with feminine ideals and norms (DuruBellat, 1997; Eagly \& Steffen, 1986). Consequently, boys and girls tend to adopt behaviors in accordance with appropriate gender roles, including sport context. 
Gender role socialization can also reflect different sport participation opportunities. Team sports are generally perceived as masculine ones and these sports are largely surrounded by men (Csizma et al., 1988; Koivula, 1995, 2001; Meaney, Dornier, \& Owens, 2002). In this context, female players involved in team sports appear to be in contradiction with gender appropriate sport participation. So female players may be subjected to gender role conflict (Scully, Reilly, \& Clarke, 1998) and can adopt more gender-appropriate behaviors (i.e., less aggression) to counterbalance the effect of a non-appropriate sport choice.

\section{Gender, Competitive Level and Aggression}

In line with the second hypothesis, the results showed that male and female players displayed more aggressive behaviors in national competitive level. The findings actually revealed a significant effect of competitive level on instrumental and hostile aggressive behaviors, both in soccer and in handball. Instrumental aggressive behaviors increase when the competitive level rises, while hostile aggressive behaviors decrease. The results are congruent with Bredemeier's (1985), Conroy et al.'s (2001) or Silva's (1983) findings. According to Goodger and Jackson (1985), instrumental aggression would progressively be integrated as performance tools. Furthermore, in compliance with Conroy et al. (2001), we can explain such results by the development of reinforcement structures towards greater tolerance and acceptation in the different competitive levels. For instance, many players and coaches consider aggressive behaviors as an important strategy for winning (Sheldon \& Aimar, 2001). Weinstein, Smith, and Wiesenthal (1995) showed that young ice hockey players are taught that engaging in aggression is often vital for team success. Victory becoming more and more important in higher competitive levels, related to social or financial aspects, all strategies, even illegitimate, are employed. Recently, Rascle, Coulomb, and Pfister (2000) demonstrated the development of coaches' verbal communications as the competitive level increased. Coaches tend to more and more disagree with the referees and to express 
positive reinforcements after instrumental aggressions. Furthermore, the higher the competitive level, the more coaches favor result feedback rather than process feedback (Chaumeton \& Duda, 1988) and consider one of their main functions is to teach players to be aggressive (Carpenter \& Yates, 1997). "Contextual forces [that] would be so strong that they [would] override the impact of sportsmanship orientations (or moral reasoning level) and become the main determinants of sportsmanship behavior" (Vallerand, Deshaies, \& Cuerrier, 1997, p. 134). So, a logic of performance is progressively adopted by players, to the detriment of sportspersonship and fair-play.

Although these explanations may be relevant, most of these studies refer to male practice. As Nixon stated (1997, p. 380), “although physically aggressive behavior is generally associated with sport, the traditional exclusion of females from sport has resulted in little attention to the aggressiveness of female athletes". Yet, the findings of the present study clearly demonstrate that it is important to consider female aggression as well as male aggression in sport, particularly with regard to competitive level. As suggested by Nixon (1997), "the possibility that both males and females become generally more aggressive as a result of their sports involvement suggests that sport socialization reinforces stereotypical gender role learning for males and teaches females to act in nonstereotypical ways" (p. 381). In the present research, even if gender difference appeared whatever the considered competitive level, the findings revealed that female players, as male players did, displayed more instrumental aggressive behaviors in higher competitive level. Nixon (1997) suggested that "female athletes seek to emulate male physical aggression and male macho values in team and contact sports as their sports become more competitive " (p.388). Another explanation could be that female players adopt an efficient style of practice more than a masculine one. The efficiency requirement for the highest competitive level in sport could be a relevant element leading female players to overcome gender stereotypes. In that perspective, 
aggressions are progressively used as performance-related tools by female players, in the same logic as male players. So females would tend to adopt behaviors more adapted to success and victory and thus behaviors qualified as masculine. The logic of performance would then surpass traditional gender roles.

Nevertheless, males and females would not accede to this state in the same way, as indicated by the significant gender $\mathrm{x}$ competitive level interaction. Male players involved in departmental level displayed instrumental aggressive behaviors more than players involved in regional level, and the latter less than players involved in national level, this process occurring both in handball and soccer. For female players, on the contrary, instrumental aggressive behaviors increased linearly as the competitive level rose, both in handball and soccer. Aggressive behaviors being generally perceived as more appropriate for men than women, male players did not hesitate to use such illegitimate behaviors from the lowest competitive level, contrary to female players. But at a departmental competitive level, players did not use such behaviors in a strategic way, due to their poor technical abilities (Coulomb \& Pfister, 1998). Control and "efficient" use of such aggressive behaviors (as tools for performance) necessitate experience and improvement of technical competencies. Female players did not use of such behaviors in departmental level, because they contradict their gender roles, but progressively adopted this strategic use of aggressive behaviors, contextual forces overriding fair play and appropriate gender attitudes. Future research could explore the reasons given by female players involved in national competitive level to use aggressions. Are aggressions actually perceived as necessary for victory by female players? In depth interviews could be very relevant to test this assumption.

\section{Gender, Competitive Level, Sport Type and Aggression}

Our last hypothesis dealt with a gender difference in aggression, being less important in handball than in soccer. The findings actually tend to confirm our assumption even if the 
gender differences remain significant in all the cases. Significant Chi-squared suggest different distribution of instrumental and hostile aggressive behaviors among handball and soccer and male and female players. On the other hand, the variance explained by gender in soccer is more important than the variance explained in handball. Finally, the increase of instrumental aggressive behaviors for female players when the competitive level rises incites to believe that gender role can be challenged by a performance-oriented logic. But Theberge (1994) pointed out that the studies in gender role conflict perspective presented some methodological and conceptual problems not considering competitive level and sport type. In accordance with Theberge, we think that gender role conflict may be more or less important and active, and so more or less easy to challenge, depending on the context. Thus, soccer is a quasi exclusively masculine sport in France: Men represent $97.6 \%$ of players, as most of the coaches and the referees, contrarily to handball that is largely feminized, so much with regard to players (35\% are female players) that coaches and referees. Consequently, female soccer players, and more particularly those involved in the highest competitive level, are faced to a double conflict: that of traditional gender stereotypes giving little value to this sport for girls, challenging with the interest for this activity; the choice of their participation in this sport already goes against established norms. And on the other hand the conflict of efficiency requirement (highlighting the role of aggression, especially for national competitive level) compared with adopting socially non-desirable behaviors for girls (aggressive behaviors). Solving these conflicts is never satisfactory: Either they lose their feminine identity adopting behaviors not appropriate to expectations and social norms, but which are part of a performing game (aggressive behaviors: choice from handball female players). In this case, they are often treated as tomboys or accused to be lesbians (Young, 1997). Either they keep their feminine identity and adopt behaviors more compliant with social expectations (less aggressions: choice from soccer female players) and they are accused of not playing soccer, 
but their "own kind of game". In some sports, this choice is not even possible since an adjusted sport is imposed as in ice-hockey with adjusted rules for feminine practice (contacts and body-checking are limited). Theberge (1997) showed that if some female players accepted this state matter reducing contacts and aggressions, others on the contrary regretted they could not say they practice the same activity as men.

Future research could explore how female soccer players involved in the highest competitive level perceive and are affected by this double gender role conflict and if some personal or environmental factors, such as ego-orientation, moral reasoning or coaches' expectations affect these perceptions and orientations. Are all female players concerned with this double conflict or do some of them not feel it the same way? 


\section{References}

Bandura, A. (1973). Aggression: A social learning analysis. Englewood Cliffs: Prentice-Hall.

Biernat, M. (1991). Gender stereotypes and the relationship between masculinity and feminity: A developmental analysis. Journal of Personality and Social Behavior, 61, 351365.

Bredemeier, B. J. (1978). BAAGI: Instrument to assess instrumental and reactive aggression. In Proceedings of the international symposium on psychological assessment in sport (pp. 136-145). Netanya, Israel: Wingate Institute for Physical Education and Sport.

Bredemeier, B. J. (1985). Moral reasoning and the perceived legitimacy of intentionally injurious sport acts. Journal of Sport Psychology, 7, 110-124.

Bredemeier, B. J. (1994). Children's moral reasoning and their assertive, aggressive, and submissive tendencies in sport and daily life. Journal of Sport and Exercise Psychology, 16, 1-14.

Buss, A. H., \& Perry, M. (1992). The Aggression Questionnaire. Journal of Personality and Social Psychology, 63, 452-459.

Carpenter, P. J., \& Yates, B. (1997). Relationships between achievement goals and the perceived purposes of soccer for semi-professional and amateur players. Journal of Sport and Exercise Psychology, 19, 302-311.

Chaumeton, N. R., \& Duda, J. L. (1988). Is it how you play the game or whether you win or lose ? The effect of competitive level and situation on coaching behaviors. Journal of Sport Behavior, 11, 157-174.

Cohn, L. D. (1991). Sex differences in the course of personality development: A metaanalysis. Psychological Bulletin, 109, 252-266. 
Colley, A., Roberts, N., \& Chipps, A. (1985). Sex-role identity, personality, and participation in team and individual sports by males and females. International Journal of Sport Psychology, 16, 103-112.

Conroy, D. E., Silva, J. M., Newcomer, R. R., Walker B. W., \& Johnson, M. S. (2001). Personal and participatory socializers of the perceived legitimacy of aggressive behavior in sport. Aggressive Behavior, 27, 405-418.

Coulomb, G. (1996). Etude comportementale et motivationnelle de l'agression dans les sports collectifs: Comparaison des pratiques féminines et masculines [Behavioral and motivational study of aggression in team sports : comparison of female and male practices]. Unpublished doctoral dissertation, Faculty of Sport Sciences, University of Mediterranean, France.

Coulomb, G., \& Pfister, R. (1998). Aggressive behaviors in soccer as related to competitive level and time: A field study. Journal of Sport Behavior, 21, 222-231.

Cox, R. H. (1985). Sport psychology: Concepts and applications. Dubuque, IA: W.C. Brown Publishers.

Csizma, K. A, Wittig, A. F., \& Schurr, K. T. (1988). Sport stereotypes and gender. Journal of Sport and Exercise Psychology, 10, 62-74.

Deaux, K., \& Lafrance, M. (1998). Gender. In D. Gilbert \& S. Fiske (Eds.), Handbook of social psychology, Vol. 1, $4^{\text {th }}$ Ed. (pp. 788-827). New York, NY: McGraw Hill.

Duda, J. L., Olson, L. K., \& Templin, T. J. (1991). The relationship of task and ego orientation to sportsmanship attitudes and the perceived legitimacy of injurious acts. Research Quarterly for Exercise and Sport, 62, 79-87.

Duru-Bellat, M. (1997). La socialisation familiale différentielle des enfants, garçons et filles: Une synthèse de la littérature européenne et anglo-saxonne [The differential family 
socialization of children, boys and girls: a synthesis of the european and anglo-saxon literature]. Carrefours de l'Education, 3, 93-107.

Duru-Bellat, M., \& Jarousse, J-P. (1996). Le masculin et le féminin dans les modèles éducatifs des parents [Masculine and feminine in parents' educational models]. Economie et Statistiques, 293, 77-93.

Eagly, A. H., \& Steffen, V.J. (1986). Gender and aggressive behavior: A meta-analytic review of the social psychological literature. Psychological Bulletin, 100, 309-330.

French Soccer Federation (2003). French Soccer Federation website: http://www.fff.fr.

Goodger, M. J., \& Jackson, J. J. (1985). Fair play: Coaches' attitudes toward the laws of soccer. Journal of Sport Behavior, 8, 34-41.

Hyde, J. S. (1984). How large are gender differences in aggression ? A developmental metaanalysis. Developmental Psychology, 20, 722-736.

Jöneskog, K., \& Sörbom, D. (1999). LISREL (Version 8.30) [Computer Software]. Lincolnwood, IL: Scientific Software International.

Kirker, B., Tenenbaum, G., \& Mattson, J. (2000). An investigation of the dynamics of aggression: Direct observations in ice hockey and basketball. Research Quarterly for Exercise and Sport, 71, 373-386.

Koivula, N. (1995). Ratings of gender appropriateness of sports participation: Effects of gender-based schematic processing. Sex Roles, 33, 543-557.

Koivula, N. (2001). Perceived characteristics of sports categorized as gender-neutral, feminine and masculine. Journal of Sport Behavior, 24, 377-393.

Loughead, T. M., \& Leith, L. M. (2001). Hockey coaches' and players' perceptions of aggression and the aggressive behavior of players. Journal of Sport Behavior, 24, 394407. 
Lytton, H., \& Romney, D. M. (1991). Parents' differential socialization of boys and girls: A meta-analysis. Psychological Bulletin, 109, 267-296.

Masters, W., Johnson, V., \& Kolodny, R. (1982). Human sexuality. Boston: Little Brown.

Meaney, K. S., Dornier, L. A., \& Owens, M. S. (2002). Sex-role stereotyping for selected sport and physical activities across age groups. Perceptual and Motor Skills, 94, 743-749.

Messner, M. A. (1990a). When bodies are weapons: Masculinity and violence in sport. International Review for the Sociology of Sport, 25, 203-220.

Messner, M. A. (1990b). Boyhood, organized sports, and the construction of masculinities. Journal of Contemporary Ethnography, 18, 416-444.

Metheny, E. (1965). Connotations of movement in sport and dance. Dubuque, IA: W. C. Brown Publishers.

Ministry of Youth and Sports (1999). Assises nationales « Femmes et Sport », rapport d'étape du groupe 4: Analyse des pratiques sportives des femmes [National conference "Women and Sport », group 4 stage report: analysis of women sport practices]. Mai, Paris (France).

Nixon, H. L. (1997). Gender, sport, and aggressive behavior outside sport. Journal of Sport and Social Issues, 21, 379-391.

Pfister, R., \& Sabatier, C. (1994). Les interactions agressives dans la pratique sportive des jeunes [Aggressive interactions in youth sport]. Enfance, 2-3, 215-232.

Rascle, O., Coulomb, G., \& Pfister, R. (1998). Aggression and goal orientations in handball: influence of institutional sport context. Perceptual and Motor Skills, 86, 1347-1360.

Rascle, O., Coulomb, G., \& Pfister, R. (2000). Communications verbales d'entraîneurs et comportements d'agression de jeunes joueurs en handball: Quelles relations ? [coaches' verbal communications and young players'aggressive behaviors in handball]. Avante, 6, 24-37. 
Riemer, B. A., \& Visio, M. E. (2003). Gender typing of sports: An investigation of Metheny's classification. Research Quarterly for Exercise and Sport, 74, 193-204.

Ryan, K., Williams, J. M., \& Wimer, B. (1990). Athletic aggression: perceived legitimacy and behavioral intentions in girls' high school basket-ball. Journal of Sport and Exercise Psychology, 12, 48-55.

Scully, D., Reilly, J., \& Clarke, J. (1998). Perspectives on gender in sport and exercise. The Irish Journal of Psychology, 19, 424-438.

Sheldon, J. P., \& Aimar, C. M. (2001). The role aggression plays in successful and unsuccessful ice hockey behaviors. Research Quarterly for Exercise and Sport, 72, 304309.

Silva, J.M. (1980). Assertive and aggressive behavior in sport: a definitional clarification. In C.H. Nadeau, W.R. Halliwell, K.M. Newell \& G.C. Roberts (Eds.), Psychology of motor behavior and sport (pp. 199-208). Champaign, Ill: Human Kinetics Publishers.

Silva, J. M. (1983).The perceived legitimacy of rule violating behavior in sport. Journal of Sport Psychology, 5, 438-448.

Stephens, D. (1998). Aggression. In J. L. Duda (Ed.), Advances in sport and exercise psychology measurement (pp. 277-292). Morgantown, WV: Fitness Information Technology.

Stephens, D., \& Bredemeier, B. J. L. (1996). Moral atmosphere and judgments about aggression in girls' soccer: Relationships among moral and motivational variables. Journal of Sport and Exercise Psychology, 18, 158-173.

Tenenbaum, G., Stewart, E., Singer, R. N., \& Duda, J. (1996). Aggression and violence in sport: An ISSP position stand. International Journal of Sport Psychology, 27, 229-236. 
Theberge, N. (1994). Toward a feminist alternative to sport as a male preserve. In S. Birrell \& C. L. Cole (Eds.), Women, sport and culture (pp. 181-192). Champaign, Il: Human Kinetics Publishers.

Theberge, N. (1997). "It's part of the game": Physicality and the production of gender in women's hockey. Gender and Society, 11, 69-87.

Tucker, L. W., \& Parks, J. B. (2001). Effects of gender and sport type on intercollegiate athletes' perceptions of the legitimacy of aggressive behaviors in sport. Sociology of Sport Journal, 18, 403-413.

Vallerand, R. J., Deshaies, P., \& Cuerrier, J. P. (1997). On the effects of the social context on behavioral intentions of sportsmanship. International Journal of Sport Psychology, 28, 126-140.

Weinstein, M. D., Smith, M. D., \& Wiesenthal, D. L. (1995). Masculinity and hockey violence. Sex Roles, 33, 831-847.

Worrell, G., \& Harris, D. V. (1986). The relationship of perceived and observed aggression of ice hockey players. International Journal of Sport Psychology, 17, 34-40.

Young, K. (1997). Women, sport and physicality. International Review for the Sociology of Sport, 32, 297-305. 
Table

Game Means (and Standard Deviations) of Instrumental and Hostile Observed Aggressive Behaviors According to Gender, Competitive Level and Sport Type for a 15-min Standard Period

Soccer Handball

Gender

\begin{tabular}{lllll}
\hline Dept. L & Reg. L Nat. L & & Dept. L & Reg. L Nat. L
\end{tabular}

Instrumental aggressive behaviors

$\begin{array}{lcccccc}\text { Females } & 1.71 & 3.80 & 4.90 & 21.16 & 25.91 & 30.68 \\ & (0.43) & (0.69) & (0.73) & (2.28) & (2.33) & (2.09) \\ \text { Males } & 10.70 & 9.98 & 12.54 & 33.40 & 30.38 & 37.86 \\ & (1.21) & (0.75) & (1.16) & (2.52) & (3.49) & (3.04)\end{array}$

Hostile aggressive behaviors

$\begin{array}{lcccccc}\text { Females } & 0.81 & 0.49 & 0.85 & 0.96 & 1.51 & 1.71 \\ & (0.43) & (0.36) & (0.34) & (0.65) & (0.84) & (0.98) \\ \text { Males } & 4.57 & 2.86 & 1.43 & 1.88 & 2.36 & 3.43 \\ & (1.52) & (0.77) & (0.49) & (0.33) & (1.35) & (1.02)\end{array}$

Note. Dept. L = Departmental Level, Reg. $\mathrm{L}=$ Regional Level et Nat. $\mathrm{L}=$ National Level. 
Figure 1. Factorial structure of observed aggressive behaviors emerging from confirmatory factor analysis in soccer (on the left) and handball (on the right).
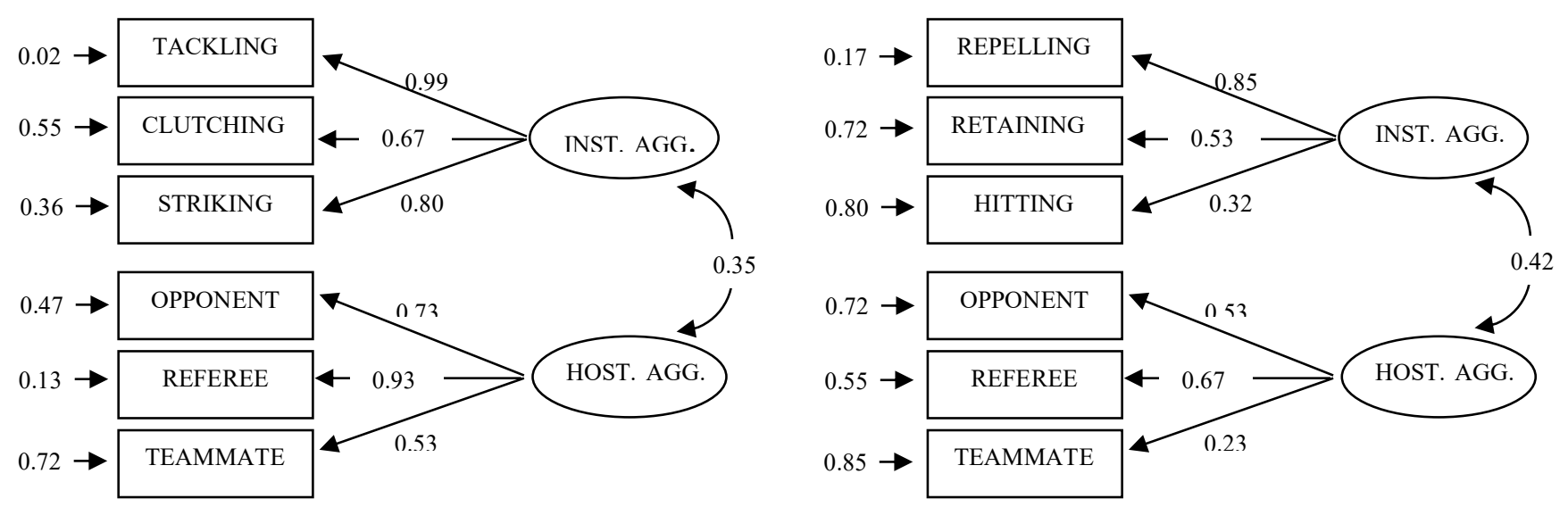
Figure 2. Team means of instrumental and hostile observed aggressive behaviors as a function of competitive level in soccer for a 15-min standard period (* indicates a significant difference with the immediate lower competitive level).

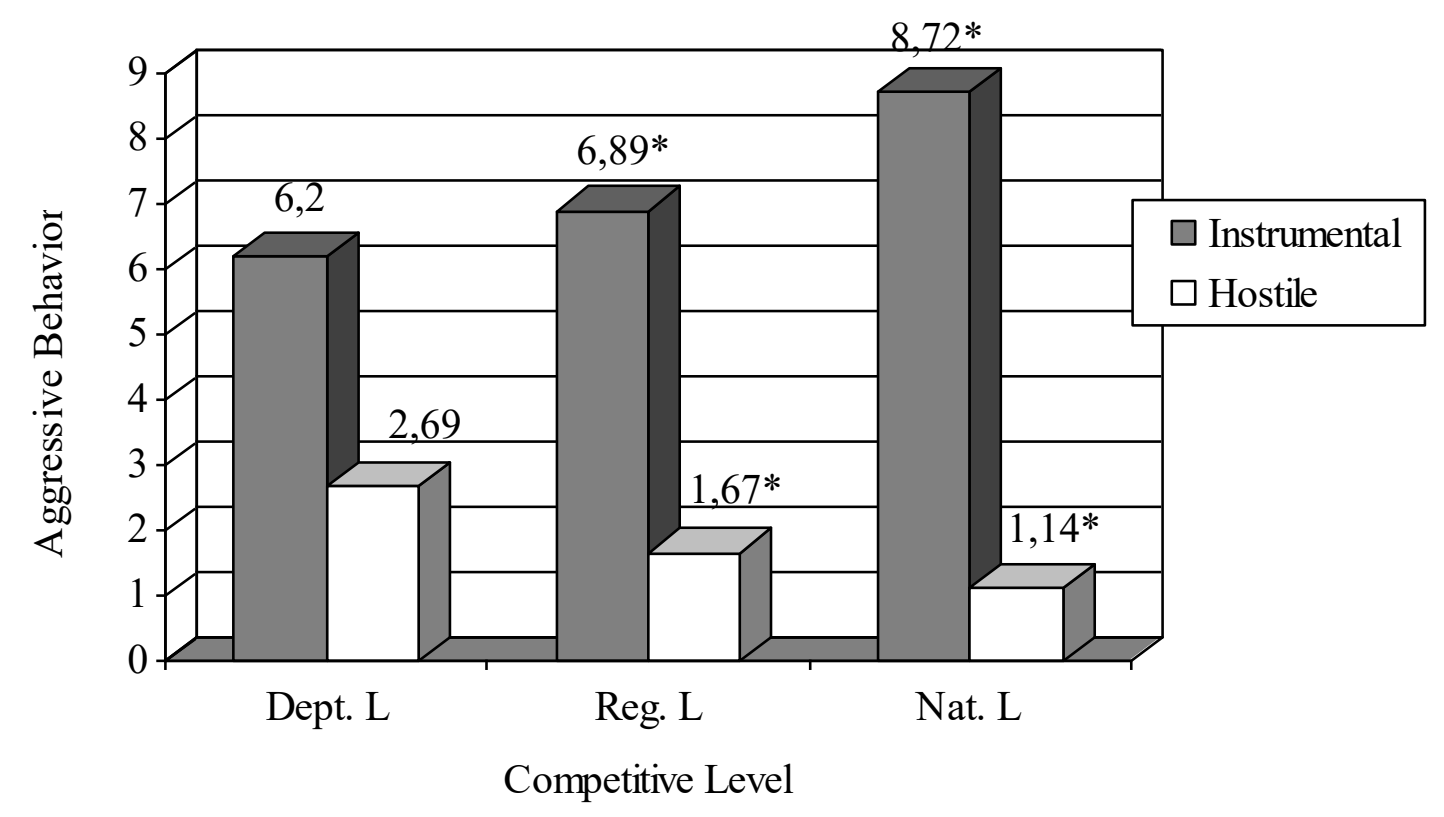


Figure 3. Team means of instrumental and hostile observed aggressive behaviors as a function of competitive level in handball for a 15-min standard period (* indicates a significant difference with the immediate lower competitive level).

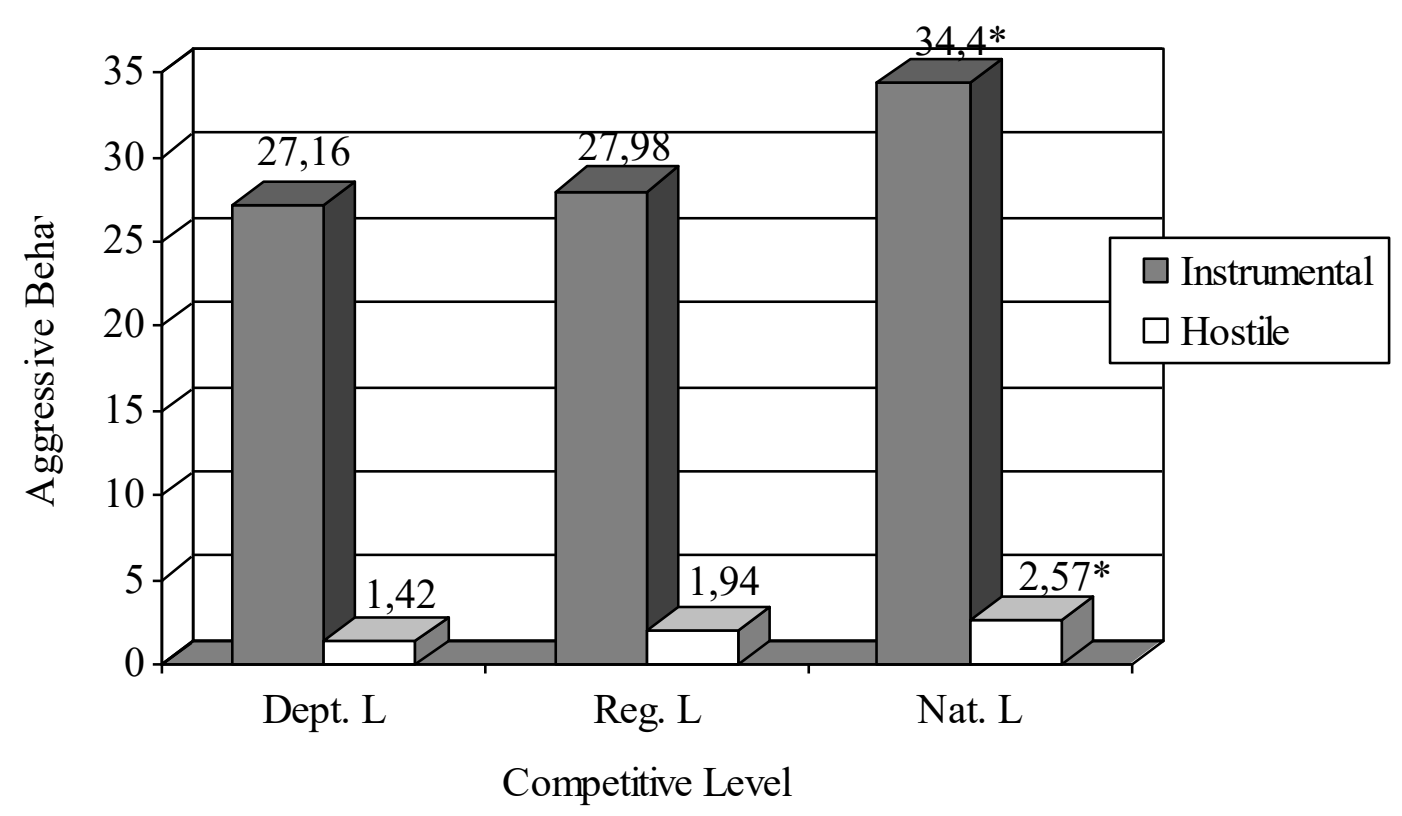

